\title{
A General Perspective about Institutional Rankings, Ranking Framework, Benefits of Rankings and Ranking Methodological Flaws and Best Approach for Being A World Class Institution
}

Article History:

Received 30.09.2021

Received in revised form 06.02.2022

Accepted

Available online

01.07.2022

\section{Ali Mohammad Ghulam ${ }^{1}$}

\begin{abstract}
Ranking scales is an important tool which serves learning outcomes. Accuracy of Ranking depends upon how accurately \& honestly the data is submitted according to the ranking methodology, how accurately Peers are giving their responses and how efficiently the ranking agencies are validating and evaluating the submitted data. However, giving more emphasis on pedagogy, teaching \& learning environment, periodic curriculum review, strengthening the existing infrastructure resource, graduate outcome in minimum stipulated time, employability including entrepreneurship and higher studies, regular evaluation \& assessments, research \& outcomes, collaborations and new course offering according to the market demand, Ranking will improve, International outlook will also improve accordingly. Ranking is essential for strategic planning and enhancement of institutional transparency and stimulating the quality culture in education. Rankings also influence national and international partnerships and collaborations. Rankings are a manifestation of global competition and are used as a policy instrument. Rankings are provoking an important debate about the quality and performance of HEIs. We can also say one of the manifestations of Rankings is to build a competitive institutional competence of world class universities. In this paper, I have discussed mainly on general perspective about institutional rankings, ranking framework, benefits of rankings and flaws in the ranking methodology.
\end{abstract}

(C) IJERE. All rights reserved

Keywords: Higher Education, rankings, university rankings, Nirf India rankings, college rankings, institution rankings, qs world university rankings, time higher education world university rankings

\section{Introduction}

According to OECD international forum (2007), Rankings give an indication of the seriousness with which many higher education institutions (HEIs), policymakers and the media attach to them. University leaders believe rankings help maintain and build institutional position and reputation; good students use rankings to 'shortlist' university choice, and key stakeholders use rankings to influence their decisions about accreditation, funding, sponsorship and employee recruitment. Almost 50\% respondents use their institutional rank for publicity purposes, in press releases, official presentations and their website. $58 \%$ are unhappy with their position: $70 \%$ want to be in the top $10 \%$ nationally, and $71 \%$ in the top $25 \%$ internationally. Over $50 \%$ have a formal process to review the results, and $68 \%$ use them as a management tool to bring about strategic, organizational, managerial and/or academic change. Rankings also influence national and international partnerships and collaborations. Rankings are a manifestation of global competition and are used as a policy instrument. Leaders say they consider a potential partner's rank prior to entering into discussion about research and academic programmes. In addition, rankings influence the willingness of others to partner with them or support their membership of academic/professional associations. Rankings are a manifestation of global competition and are used as a policy instrument. Many governments proclaim the desire to establish at least one, if not more, 'world class' universities. Rankings are provoking an important debate about the quality and performance of HEIs, how they should be defined and measured, by whom and for what purpose. There are big policy implications, including a role for educating public opinion and opinion formers - many of whom make ambitious statements without understanding their full impact for higher education and society. Please also see page 11 of Marope P.T.M., Wells P.J. and Hazelkorn E. (eds) (2013), United Nations Education, Scientific, and Cultural Organization, Rankings and Accountability in Higher Education: Uses and Misuses

According to Mu-Hsuan Huang (2012), the waves of globalization encourage the competition among universities on a global basis. Country-wide university rankings become inadequate.

As the issues surrounding rankings became clearer, the government has taken a more holistic view about ranking. The Minister of Higher Education has expressly articulated that universities should not be 'obsessed with ranking' (Khaled Nordin, 2011). Instead the government is focusing more on making the education system 'world class' to accommodate the increasing entrants to higher education. Please also see Marope P.T.M., Wells P.J. and Hazelkorn E. (eds) (2013), United Nations Education, Scientific, and Cultural Organization, Rankings and Accountability in Higher Education: Uses and Misuses. I have discussed and proposed very nicely in the same context below.

There is also a matter of debate; either to think on 'world-class' higher education systems' or 'world-class' higher education institutions. As per my view both are linked interdependent. But first priority should be on 
the 'world-class' higher education systems' then obviously a 'world-class' higher education institutions' will emerge. Please see my approach proposed and discussion below.

Why Quality, Accreditation, Ranking and Rating

A rating question asks us to compare different items using a common scale of 1-10. An individual Evaluation. While a ranking question asks us to compare different items directly to one another. Evaluation based on participation of more than one Institutions. Quality, Accreditation, Ranking and Rating is a tool for quality assurance mechanism that helps the students to choose courses and institutions on the basis of grades or ranks. It would enable them to make informed choice. However, assessing the quality of education is an extremely difficult and delicate exercise. Education is a service that is not a one-shot affair. Delivery of education is a process and lasts over a period of time. In terms of learning, education is a continuous process. Primarily, level of motivation of the teachers along with the infrastructure, governance of the institutions and course curriculum determine the quality, as it is also discussed and very accurately proposed in details in point Bottom-up Approach proposed below.

Following agencies in India are engaged in Rating the Higher Education Institutions through accreditation by bodies in India such as UGC (University Grants Commission) or NAAC (National Assessment and Accreditation Council) or NBA or External Peer Review by the Ministry of Education. Currently Ministry of Education has constituted a non-profit Section 8 company in collaboration with IITKGP, IITD and IITM for conducting accreditation of Colleges and Institutions from IIT side as the NBA has too much load.

Any Institution participate in the ranking process, in order to evaluate performance in relation to the Ranking, an Institute should investigate ranking process which is carried out by the ranking agency, how well this is done.

\section{Key Assessment Parameters for College/Institution/University of World Class Proposed}

We may project College/Institution/University of World Class in the following context:

1) Excellence in global context and have been able to deliver the quality output.

2) $100 \%$ fetching a pay scale which is equal to or more than their return on investments.

3) Encouraging research-based projects and fostering a mind-set of innovation.

4) Producing best entrepreneurial and Mobilizing Human Capital for Entrepreneurships.

5) Introducing new programmes as per the market demand.

6) Having good foreign collaboration.

7) Periodically improving the curriculum.

8) Developing the teaching pedagogy.

9) Continuous endeavour in enhancing the intellectual activities

\section{Two-Way Benefit Of Participating in College/Institutional/University Rankings [Bottom-Up or Top-Down} Approach]: A Continuous Effort to be of World Class Nicely Proposed

A weaker College/Institution/University, in sense of Academic, Research, Employability, Outreach, Inclusivity \& Diversity, Collaboration, Internationaliztion and Infrastructure Resources will participate in rankings and will assess each score obtained after the announcement of results. Get motivated through the bench-mark with the regional top score of the \#1. College/Institution/University and will pick the weak areas and will exercise more effort on these areas to continuously improve in the forthcoming years.

A Stronger College/Institution/University will participate in rankings, be it national or international, and will assess each score obtained after the announcement of results. It will do several bench-markings with respect to the top scores of the \#1. College/Institution/University and will further strengthen itself to join the race to achieve the top score in the forthcoming years.

Benefits in the real sense of the rankings will also rely on the robust ranking methodologies, considering regional factors, submitting factual data based on the ranking data definition \& proper evaluation of submitted data and finally getting appropriate \& accurate responses from all peers during the survey process as it is also discussed above.

\section{A. Bottom-up Approach Proposed}

1) To produce the best products and ensure the best placement, facilitating some of them by choice to opt for Higher Studies and facilitating some of them by choice to opt to setup their own entrepreneurships/start up/incubation and finally trying to get the aggregating score to be a $100 \%$ graduate outcome every year.

2) Assessment of retention and reasons for Drop-out through conducting survey and getting responses from each employer about where our graduates are placed after six months of graduation. 
3) Assessment of retention and reasons for Drop-out through conducting survey and availing responses from each graduate on where they are placed or engaged after six months of graduation.

4) The outcomes from both the assessments and responses [in 2) and 3)] reflect the strengths and weaknesses of our pass outs. If the responses received are rather adequate then we can say that our Curriculum \& Courses offered, exactly fit/don't fit the global perspective and our teaching, guidance \& evaluation standards, which are considered as a key indicator, are also either excellent or need to be further strengthened.

5) To maintain the diversity in sense of region, caste, gender, community and international students baring the factor whether our College/ Institution/University is fairly accessible in sense of the communication, city, region and country.

6) If we are able to meet challenges mentioned in point 5 , then we are obviously ensuring them adequate number of teachers (national and foreign), giving more emphasis on pedagogy, teaching \& learning environment, periodic curriculum review, good academic \& research infrastructure resources, flexible curricula and course offering (core, interdisciplinary, multidisciplinary and joint), a large number of academic and research collaborations to attract foreign and indigenous students, producing best entrepreneurial and mobilizing human capital for entrepreneurships, $100 \%$ fetching a pay scale which is equal to or more than their return on investments, good accommodation facility, being non bias in any sector, providing best food \& maintaining hygiene, offering awards and honors for the best work, offering various grants for the excellent works of the teachers, staffs \& students, fairly dealing with academic administrative matters in a fast pace, providing enough space for the entertainment, sports and various events of our students and finally continuous endeavour in enhancing the intellectual activities.

7) To give emphasis on revenue generation through qualitative and quantitative consulting and sponsored research Projects, collaborative research, IPRs \& Patents commercialization and through organizing various outreach programs on demand.

8) Sharing best practices and innovations among other Institutions, Research laboratories and Industries.

9) Finally, I suggest the identification of restructuring actions in research, organizational restructure, restructuring in curriculum that bridges EU and US model, target Ph.D. students and internationalization, hire talented scholars and restructuring in management and marketing of higher education.

10) If we meet Points 1) to 9), then obviously we would obtain good scores and ranking positions in any National or International Rankings.

\section{B. Top-down Approach Proposed}

Here, FIRST, each College/Institution/University participates in the National and Interna tional Rankings, obtains a ranking position and scores on various parameters based on ranking framework and factual data submitted, and based on appropriate responses from each peer, then formulates the action plan accordingly to strengthen the Institute in all spheres as it is proposed above in points 1) to 9), using the bench-marks to see where they are leading and where they are trailing and to obtain better ranking scores and poitions in the forthcoming years.

\section{Emergence of Rankings and Ranking Methodology}

\section{1) Academic Ranking of World Universities}

Marope P.T.M., Wells P.J. and Hazelkorn E. (eds) (2013), United Nations Education, Scientific, and Cultural Organization, Rankings and Accountability in Higher Education: Uses and Misuses, Academic Ranking of World Universities by Shanghai Jiao Tong University in China emerged in 2003. I have not taken into consideration this Ranking in this paper.

2) NIRF India Rankings

\section{Emergence}

According to NIRF INDIA RANKINGS (2021, the National Institutional Ranking Framework (NIRF) was approved by the MHRD and launched by Honorable Minister of Human Resource Development on 29th September 2015.

\section{Ranking Methodology}

NIRF INDIA RANKINGS (2021), National Institutıonal Rankıng Framework, Methodology For Ranking of Academic Institutions in India, Rankıng Metrics for Overall, summary of Ranking Parameters and Weightages- 2021 (Overall) is given below.

Sr. No. Parameter Marks Weightage


1 Teaching, Learning \& Resources $\quad 100 \quad 0.30$

A. Student Strength including Doctoral Students(SS):

20 marks

B. Faculty-student ratio with emphasis on permanent faculty (FSR):

25 marks

C. Combined metric for Faculty with PhD (or equivalent) and Experience (FQE):

20 marks

D. Financial Resources and their Utilisation (FRU):

20 marks

E. Online Education: Online Completion of Syllabus \& Exams and Swayam (OE):

15 marks

2 Research and Professional Practice $100 \quad 0.30$

A. Combined metric for Publications (PU):

35 marks

B. Combined metric for Quality of Publications $(\mathrm{QP})$

35 marks

C. IPR and Patents: Published and Granted (IPR):

15 marks

D. Footprint of Projects and Professional Practice (FPPP):

15 marks

3 Graduation Outcomes $100 \quad 0.20$

A. Metric for University Examinations(GUE):

B. Metric for Number of Ph.D. Students Graduated (GPHD):

60 marks

40 marks

4 Outreach and Inclusivity $\quad 100 \quad 0.10$

A. Percentage of Students from Other States/Countries (Region Diversity RD): $\quad 30$ marks

B. Percentage of Women (Women Diversity WD):

30 marks

C. Economically and Socially Challenged Students (ESCS):

20 marks

D. Facilities for Physically Challenged Students (PCS):

20 marks

5 Perception $100 \quad 0.10$

A. Peer Perception: Academic Peers and Employers (PR):

100 marks

\section{3) QS World University Rankings}

Emergence

As discussed below at point 4) below under "Emergence", Elsevier Scopus became its data provider.

\section{Ranking Methodology}

According to Marope P.T.M., Wells P.J. and Hazelkorn E. (eds) (2013), United Nations Education, Scientific, and Cultural Organization, Rankings and Accountability in Higher Education: Uses and Misuses, the ranking methodology for QS World University Rankings is given below.

Academic reputation $(40 \%)$

Employer reputation (10\%)

Faculty/Student Ratio (20\%)

Citations per faculty $(20 \%)$

International faculty ratio $(5 \%)$

International student ratio (5\%)

\section{4) Time Higher Education World University Rankings}

\section{Emergence}

According to Marope P.T.M., Wells P.J. and Hazelkorn E. (eds) (2013), United Nations Education, Scientific, and Cultural Organization, Rankings and Accountability in Higher Education: Uses and Misuses, the Times Higher Education of England quickly developed its own global ranking system after the appearance of ARWU. It was emerged in 2004 and the Times Higher Education Supplement published its 'World University Rankings' in November of 2004. After 2005, the ranking was co-published by Times Higher Education and Quacquarelli Symonds Company every year as THE-QS World University Rankings. In 2010, Times Higher Education terminated its collaboration with Quacquarelli Symonds and both began to publish their own global ranking lists. While the new QS ranking fully retained the methodology of previous THE-QS rankings, the Times Higher Education ranking increased its number of indicators to thirteen and Thomson Reuters became its data provider (Times Higher Education, 2010).

The Times ranking uses a mixture of reputation, research output, and other quantitative input data to determine the top School / College / Institution / University as it is mentioned below.

\section{Ranking Methodology}

According to Times Higher Education World University Rankings 2022: methodology (2021), the ranking methodology is given below. 
Teaching (the learning environment): $\mathbf{3 0} \%$

- Reputation survey: $15 \%$

- Staff-to-student ratio: $4.5 \%$

- Doctorate-to-bachelor's ratio: $2.25 \%$

- Doctorates-awarded-to-academic-staff ratio: $6 \%$

- Institutional income: $2.25 \%$

Research (volume, income and reputation): $\mathbf{3 0} \%$

- Reputation survey: $18 \%$

- Research income: 6\%

- Research productivity: $6 \%$

Citations (research influence): $30 \%$

International outlook (staff, students, research): $7.5 \%$

- International-to-domestic-student ratio: $2.25 \%$

- International-to-domestic-staff ratio: $2.5 \%$

- International collaboration $2.5 \%$

Industry income (knowledge transfer): $2.5 \%$

\section{Observations on the Above-Mentioned Ranking Frameworks and the Ranking Process}

According to Marope P.T.M., Wells P.J. and Hazelkorn E. (eds) (2013), different global rankings have different purposes, and they only measure parts of universities' activities.

More important than what rankings judge is how they do the judging.

According to Luke Myers and Jonathan Robe (2009), tt is argued that one ranking system based on a certain set of criteria and weighting cannot possibly judge the quality of all institutions of higher education in a fair and accurate manner.

Rankings with diverse methodologies should be encouraged. If a good college/institution/university is situated in a backward/poor country, it often gets placed way lower than it should, in rankings. We can judge that a College/Institution/University is 'good' or 'bad' on the basis of Key Assessment Parameters for College/Institution/University of World Class Proposed and Bottom-up Approach Proposed as it is discussed above and it doesn't matter whether it obtained a 'good' or' bad' position in the rankings.

There are some flaws in the International Rankings (QS and THE) such as they don't consider some additional parameters in details such as being considered in NIRF India Rankings, Teaching, Learning \& Resources, Research and Professional Practice, Graduation Outcomes outreach and inclusivity, awards and honors. According to Zoljargal Dembereldorj (2018), stating about inclusion of a reasonable tool to measure the research quality of a university through some carefully selected indicators related to the quantity and quality of its scientific production and the excellence of its students and alumni, the information it provides, when properly used, allows us to gain a useful insight into the research performance of whole university systems (Docampo, 2010).

According to Mu-Hsuan Huang (2012) and Shohib Muhammed Wildan (2018), relatively high analytical weightings on reputational surveys have led Quacquarelli Symonds (QS) World University Rankings to criticisms over the years. Some other issues are also discussed in this paper.

Rankings apply a combination of indicators that might not represent universities' particular missions, and often overlook societal impact or teaching quality. Elizabeth Gadd (2020), has also discussed other issues in his article.

According to Igor Chirikov (2021), the credibility of rankings is based on a belief that rankers provide impartial information for prospective students, university administrators, and policy makers. It is implied that all universities are evaluated equitably or at least according to a uniform set of criteria. However, rankers face conflicts of interest when, in addition to objectively evaluating universities' performance, they offer these universities fee-based analytical, consulting, and advertising services. The conflicts of interest potentially interfere with the objectivity of measures used in rankings and may provide some universities advantages that are not related to their institutional quality. Biased measures could misinform prospective students, universities, governments, and funders about global standings of universities and countries.

According to F.J. Anthony van Raan (2005), peer review procedures and bibliometric analysis are the main methods to evaluate research performance of universities. So the most crucial question is: how much effort is a reliable evaluation of an entire university, and, as a consequence, will such an evaluation be possible for all universities 
in the world, in a short period of time, and against reasonable costs? Brendan O Malley (2016), in the HEPI also claimed that Global university rankings data are flawed in many aspects. Muhammad Ashraf Fauzi et.al (2020) has also discussed in the same context. According to The Irish Times, Why university rankings are flawed (2016), The institute's research indicates rankings fail to identify the "best" universities, given the numerous functions higher education institutions fulfill that are not measured. It says that it is unwise to give tables so much weight given the data used is inherently unreliable.

We also observe that, if we look at the huge differences between the rank given to the same college / institution / university in different tops, it might actually make it harder for us to assess the true value of that college / institution / university.

According to Mustafa Kayyali (2020), for example, Oxford University can lead another university in one ranking while it would be lesser that the same university in a different ranking in 2019 edition for all rankings institutions.

However, this is due to, there could be many relative factors such as ranking methodologies, number of universities considered and ranked. But it creates confusion. Therefore, Rankings are clearly less than perfect. Reputation survey is also a cause of concern. Every college / institution / university must provide a list of academic peers and employers' contacts to the ranking agencies which are constantly in touch with the college / institution / university and are well aware of the strengths and weaknesses of the college / institution / university. Then they can accurately give their responses to the ranking agencies during the survey process. Each academic peer and employer should also take the utmost priority to answer the ranking agencies queries accurately.

We can not also deny, in poor and developing countries, access of foreign teachers and students is less compared to the developed countries. Due to this, in these parameters, these countries always obtained fewer score. Hence the fact, their ranking position also falls. Therefore, some additional measures, may also be considered in the ranking methodology.

It is also clear, even some university leaders know the rankings are flawed but they need to participate in rankings to make the Institutions more visible and as they realize if they don't pay any attention to rankings they could lose international students.

However, we can say results obtained through participation in rankings cannot be perfect, but it would be useful to certain extents, such as how government measures research excellence, whether an undergraduate or graduate student and their parents are opting for the ranked college / institution / university, whether company selects the ranked college / institution / university as a partner and whether a funding body invests in the college / institution / university for research. Rankings can also increase college / institution / university's visibility and thus also play a role in attracting international students as it is also discussed above.

According to Wikipedia, QS World University Rankings (2021), the QS World University Rankings have been criticized by many for placing too much emphasis on peer review, which receives $40 \%$ of the overall score. Some people have expressed concern about the manner in which the peer review has been carried out ${ }^{[43]}$ . In a report, ${ }^{[44]}$ Peter Wills from the University of Auckland wrote of the THE-QS World University Rankings.

According to Marope P.T.M., Wells P.J. and Hazelkorn E. (eds) (2013), bibliometric indicators such as publications and citations are relatively credible for measuring the research performance of large entities, but problems and shortcomings still occur when they are used to compare universities worldwide. Many global rankings choose Thomson Citation Indexes and many choose Elsevier Scopus as their bibliometric sources, therefore only publication output and only those published in indexed journals are taken into account.

About the NIRF India rankings, there should be some additional measures in the ranking methodology between the government funded and self-financed funding College/Institution/University.

Rankings vs. Internal Assessment and Proposed to Introduce Inter-Departmental Race

According to Luke Myers and Jonathan Robe (2009), James Schmotter, then assistant dean of Cornell's Johnson Graduate School of Management, argued in 1989 that colleges and universities had only themselves to blame for the rise of college rankings because higher education had failed to put forward its own system of evaluating quality that was relevant or intelligible to consumers. ${ }^{60} \mathrm{Tw}$ o decades later, this criticism remains accurate, and college rankings continue to be an important starting place for students attempting to sort through the thousands of higher education institutions in the United States. In light of these important functions that rankings provide, Kevin Carey, a researcher for Education Sector, writes that higher education's anti-rankings sentiment is illegitimate because it reflects "an aversion to competition and accountability that 
ill serves students and the public at large." ${ }^{61}$. Academic quality rankings do, however, face many legitimate criticisms that should always be acknowledged and weighed in their discussion and use.

Nowadays, some Institutions are now undergoing through accreditation and External Peer Review process. Some Institutions or a unit of the Institution is also undergoing through accreditation from foreign accreditation agencies.

Inter-Departmental Race Proposed: As per my view, Institution may also conduct the internal rankings among the all academic units identifying some important indicators to introduce the inter-departmental race, awards and honours for above the threshold to top 3 every year, and this will give a constant pressure among the academic units to maintain the academic \& research outcomes, employability and visibility. This can be named as "do-it yourself" (DIY) rankings. Do-it-yourself rankings will also provide better information to consumers as well with the prepackaged rankings. We cannot ignore, College/Intuition/University Rankings are also accountable, and however, improvement in the design and execution of rankings is required.

\section{Some Additional Measures Proposed to Improve the Rankings Within the Existing Framework}

Bench-marks should be done at least with the next top 9 Institutions and see where they are leading and where they are trailing. Then share this info with the Institutions leaders so that they can reformulate their strategies for the next year.

Thorough study of the ranking framework and the data definition given by the ranking agencies should be done. Institutions should try to collect complete existing data from all intuitional sources accordingly, validate the data collected, populate the data according to the data definition in their sheet provided, compare the sheet with the last year submission, jointly review the final data sheet and then finally submit the data.

Institutions may try to fast track their rankings by hiring in foreign academics with a high publication rate. This will increase the ratio of international staff, publication rates and the average citation rate, as well as help in increasing positive impressions of the institution, which is all-important for the entirely subjective reputational measure.

Institutions should also try to inbound some foreign students through MoUs and Multi-Institutional programs to join the full-time programs, semester away or spend at least three to six month for their research. Similarly, in the case of foreign teachers, they should also spend at least three to six month in teaching and research.

Institutions may also provide an updated list of academic peers and employers' contacts to the ranking agencies, which are constantly in touch with the Institutions and are well aware about the strength and weaknesses of the college / institution / university.

Publication of Quarterly Institutional level Newsletter / Magazine focusing on Courses / Pedagogy / Teaching / Research / Innovations / Publications / Commercialisations / Collaborations / International Presence / a list of world's most innovative, creative, wealthy, entrepreneurial, and/or philanthropic individuals that the Institute is producing and circulate these materials globally am ong top universities / Institutions and also circulation these materials during various events to increase the perception.

Always encourage for the research-based projects and foster a mind-set of innovation to increase the number of research projects and IPRs and income through research and IPRs.

Always encourage for the best entrepreneurial for mobilizing human capital for entrepreneurships and increase in the number of entrepreneurial income from start-up/incubation. Each institution must have a Science \& Technology Enterpreneurship Development Cell that will poovide financial, skill and motivational supports to graduates who are opting for the enterpreneusrhip rather than chosing for job or higher studies..

Always encourage to increase the No. of outreach programme and income to be generated from. Outreach programmes for the executive development, short-term courses, conferences, seminars, symposia, joint and multi-institutional.

\section{OBSERVATIONAL METHOD}

I have discussed and proposed two of the best approaches for being a World Class Institution; 1) Bottom up Approach and 2) Top-down Approach including suggestions for inter-departmental race through conducting internal institutional level rankings. In case of bottom-up approach, each College/Institution/University initially must give more emphasis on strengthening the quality in all spheres as it is proposed in the above points 1) to 9) then participate in the domestic and world university rankings to obtain better ranking position and scores in each parameter, whereas in the case of top-down approach, firstly, each College/Institution/University participates in the National and International Rankings, obtains a ranking 
position and scores in various parameters based on ranking framework, the factual data submitted, and appropriate responses from each peer, then formulate the action plan accordingly to strengthen the Institute in all spheres as it is proposed above in the points 1) to 9), using the bench-marks to see where they are leading and where they are trailing and to obtain better ranking scores and position in the forthcoming years. If any Institution has more than one academic unit, to strengthen overall quality of the Institute, it may also conduct internal rankings at the institutional level among the academic units identifying some important indicators to introduce the inter-departmental race, awards and honours for being above the threshold, to the top 3 every year. This will create a constant pressure on the academic units to maintain the academic \& research outcomes, employability, collaboration, internationalization and visibility.

\section{Conclusion}

In this paper, I have systematically discussed about the three different ranking agencies, ranking methodologies they are adopting, what the flaws in their ranking methodologies are, the ranking process and what the pros and cons of rankings are. I hvae also discussed well, on how to perform well within the existing ranking framework. Finally I have discussed and proposed the best approaches for being a World Class Institution. More effort must be made by each ranking agency to introduce robust ranking methodology and framework, then validate, evaluate and process the data submitted by each participating college / institution / university. Flaws in the ranking framework should also be minimized so that students, their parents and the policy and decision maker can take the right decision based on the ranking results.

\section{Acknowledgment}

I am engaged in the Institutional World and Domestic Rankings since 2016. I was also engaged in the External Peer Review and Accreditation process. I have 28 years experience of IT of multi-various domains. I am also involved in Research. These factors have encouraged me to right this paper.

\section{Declaration of interest}

There is no conflict of Interest. A Systematic and positive approach for being a world class Institution.

\section{REFERENCES}

Ashraf, M. F. et.al. (2020). University rankings: A review of methodological flaws. Issues in Educational Research, 30(1).

Chirikov, I. (2021). Does conflict of interest distort global university rankıngs? UC Berkeley Research and Occasional Papers Series.

Craig, O. (2021). QS world university rankings - methodology. Retrieved from: https://www.topuniversities.com/qs-world-university-rankings/methodology

Dembereldorj, J. (2018). Review on the impact of world higher education rankings: institutional competitive competence and institutional competence. International Journal of Higher Education,7(3),25-35.

Fauzi,M.A.,Tan,C.N.L.,Daud,M. \& Awalludin,M.M.N. (2020). University rankings: A review of methodological flaws. Issues in Educational Research, 30(1).

Gadd, E. (2020). University rankings need a rethink. nature, WORLD View. Retrieved from: https://www.nature.com/articles/d41586-020-03312-2.

Huang, M.H. (2012). Opening the black box of QS world university rankings. Research Evaluation, 21(1), 71-78.

Kayyali, M. (2020). Pros and cons of university rankings. Project: Higher Education Quality and Assessment GroupHEQAG.Retrievedfrom:https://www.researchgate.net/publication/338676024_Pros_and_Cons_of_ University_Rankings.

Lafon, V. (2007). Programme on institutional management in higher education. OECD International Forum. Retrieved from: https://www.oecd.org/education/imhe/39802910.pdf.

Luke, M. \& Robe, J. (2009). College rankings, history, criticism and reform. Center for College Affordability and Productivity. A Report from the Center for College Affordability and Productivity.

Malley, O. B. (2016). Global university rankings data are flawed. Higher Education Policy Institute (HEPI). Retrievedfrom:https://www.universityw orldnews.com/post.php?story=20161215001420225\#: :text=HEP I\%20says \%20there\%20may\%20be,to\%20common\%20definitions\%20and\%20standards\%E2\%80\%9D.

Marope, P.T.M., Wells, P.J. \&Hazelkorn, E. (2013). Rankings and accountability in higher education: uses and misuses. United Nations Education, Scientific, and Cultural Organization.Retrieved from: https://www.qs.com/rankings-and-accountability-in-higher-education-uses-and misuses/\#: :text=The\%20book\%2C\%20entitled\%20Rankings\%20and,of\%20current\%20and\%20proposed $\% 20$ methodologies. 
Nirf India Rankings (2021). National institutional ranking framework, methodology for ranking of academic institutions in India, (Ranking metrics for overall). Ministry of Human Resource Development. Retrieved from: https://www.nirfindia.org/nirfpdfcdn/2021/framework/Overall.pdf.

Raan, A.F.J.V. (2005). Challenges in ranking of universities. First International Conference on World Class Universities, Shanghai Jaio Tong University, Shanghai. Retrieved from: https://www.researchgate.net/publication/250794968_Challenges_in_Ranking_of_Universities/link/0 a85 e5320523ebdb5b000000/download.

Ross, D. (2021). The times higher education world university rankings 2022: Methodology. The World UniversitiesInsightsLimited.Retrievedfromhttps://www.timeshighereducation.com/sites/default/files/brea king_news_files/the_2022_world_university_rankings_methodology_31082021_final.pdf.

Shohib, M.W. (2018). Higher education rankıng and quality assurance: 1ssues and critical assessment (general problem). Jurnal Pendidikan Agama Islam,1(1),11-28.

Sowter, B. (2021). Wikipedia, QS World university rankings. Quacquarelli Symonds Limited. Retrieved from:https://council-icc.org/wp-content/uploads/QS_World_University_Rankings.pdf.

The Irish Times (2016). Why university rankings are flawed. The Irish Times View. Retrieved from:https://www.irishtimes.com/opinion/editorial/why-university-rankings-are-flawed-1.2908505. 